\title{
TEMPO VERBAL, MODO VERBAL E A CONCEPÇ̃̃̃ DA REALIDADE EM PORTUGUÊS
}

\author{
Jussara ABRAÇADO (D $\boldsymbol{\Delta}$ \\ Universidade Federal Fluminense (UFF)
}

RESUMO

Sempre que pensamos ou falamos sobre situações ou eventos, atribuímos-Ihes um estatuto na realidade. Assim sendo, uma questão crucial é: como conceptualizamos a realidade? A resposta para essa questão é essencial para a compreensão do uso que fazemos do tempo verbal e do modo verbal, uma vez que são recursos gramaticalizados que nos permitem localizar a situação conceptualizada numa área específica da (ir)realidade, ou seja: (i) no plano da realidade passada ou imediata, se a situação for conceptualizada como factual; (ii) no plano da realidade não estabelecida, se a existência da situação não for aceita; e (iii) no

ช

\section{OPEN ACCESS}

EDITORES

- Miguel Oliveira, Jr. (UFAL)

- René Almeida (UFS)

AVALIADORES

- Diogo Pinheiro (UFRJ)

- Janderson de Souza (USP)

DATAS

- Recebido: 22/10/2020

- Aceito: 26/12/2020

- Publicado: 06/03/2021

\section{COMO CITAR}

ABRAÇADO, Jussara (2021). Tempo verbal, modo verbal e a concepção da realidade em português. Cadernos de Linguística, v. 2, n. 1, p. 01-17. plano da realidade projetada ou potencial, se a realização de uma situação futura for conceptualizada, respectivamente, como previsível ou apenas possível. Este ensaio, que se baseia teoricamente na Gramática Cognitiva (Langacker, 1991, 1999 e 2003), tem por proposta abordar a relação entre o tempo verbal, modo verbal e a conceptualização da realidade em português. Para tanto, são apresentados e discutidos exemplos de diferentes situações noticiadas em informativos on-line e extraídas da página de resultados da ferramenta de busca Google.

\section{ABSTRACT}

Whenever we think or talk about situations or events, we give them a status in reality. So, a crucial question is: how do we conceptualize reality? The answer to this question is essential for understanding how we use the verbal tense and the verbal mood, since they are 
grammatical resources that allow us to locate the conceptualized situation in a specific area of (ir) reality, that is: (i) at the level of past reality or immediate reality, if the situation is conceptualized as factual; (ii) at the level of reality not established, if the existence of the situation is not accepted; and (iii) at the level of projected reality or potential reality, if the occurrence of a future situation is conceptualized, respectively, as predictable or only possible. This essay, which is theoretically based on Cognitive Grammar (Langacker, 1991, 1999, 2003), aims to approach the relationship between the verbal tense, the verbal mood and the conceptualization of reality in Portuguese. For that, examples of different situations extracted from online news, obtained in the Google search tool, are presented and discussed.

\section{PALAVRAS-CHAVE}

Tempo Verbal; Modo Verbal; Concepção de Realidade; Português; Gramática Cognitiva.

\section{KEYWORDS}

Verbal Tense; Verbal Mood; Conception of Reality; Portuguese; Cognitive Grammar. 


\section{INTRODUÇÃO'}

Nas diferentes abordagens sobre tempo linguístico, há consenso em torno de sua natureza eminentemente dêitica e de que as situações são ordenadas a partir do presente, mais específicamente, do evento do ato de fala ou do momento da enunciação, conforme descreve Fonseca (1996, p. 44; grifos da autora):

\footnotetext{
O tempo, tal como o concebemos através da linguagem, é de natureza dêitica: presente, passado e futuro não são noções absolutas, são relativas ao momento de enunciação. A interpretação semântica de advérbios temporais como hoje, ontem, amanhã, ou de tempos verbais como estou, estive, estarei, pressupõe uma prévia identificação pragmática do momento de enunciação (...).
}

No que se refere ao modo verbal, também é consensual relacionar seu uso à avaliação que o falante faz sobre a situação a que se refere, considerando-a real, irreal, possível ou não.

Neste texto, a abordagem do tempo e do modo verbais não se distancia das demais nos aspectos destacados e tidos como consensuais. Entretanto, na esteira de Langacker (1991, 2002 e 2003), temos como proposta relacionar o emprego do tempo e do modo à concepção de realidade e, para além disso, demonstrar como tal relação se assenta em português, tendo como base diferentes situações ocorridas, ocorrentes e tidas como sujeitas ou não a ocorrem, noticiadas em informativos on-line e extraídas da página de resultados da ferramenta de busca Google com o filtro 'notícias' ativado. Para tanto, começamos por apresentar a proposta de Langacker em que nos baseamos.

\section{TEMPO, MODO E CONCEPÇÃO DE REALIDADE}

Tendo como fundamento o processo de conceptualização, que corresponde à apreensão, em termos cognitivos, de uma dada entidade ou situação (objeto de conceptualização) por um conceptualizador (sujeito de conceptualização), Langacker (1991) chama a atenção para a forma como conceptualizamos situações que ocorrem ou que estão sujeitas ou não a ocorrerem no mundo. De acordo com o autor, sempre que pensamos ou falamos sobre situações, atribuímos-lhes um estatuto relativo à realidade, situando a situação objeto de conceptualização dentro ou fora da realidade. E, embora se possa entender a realidade como uma entidade objetiva, que independe das pessoas, um dos fundamentos da Linguística Cognitiva é o de que o conhecimento que possuímos da realidade é

\footnotetext{
1 Este ensaio constitui uma versão ampliada de conferência proferida no evento ABRALIN ao Vivo.
} 
fragmentado, isto é, sabemos que conhecemos certas situações, mas sabemos também que desconhecemos ou ignoramos outras e que, portanto, nosso conhecimento sobre determinados fatos pode ser incompleto ou até mesmo falso.

De acordo com Langacker (1991), há perspectivas diferentes e comuns de realidade. Há pessoas com perspectivas de mundo e da realidade diferentes da nossa. No entanto, levando-se em conta que parte importante do nosso conhecimento do mundo é comum à espécie humana e é cultural, podemos supor que haja um grau considerável de concepções semelhantes da realidade. Ademais, conforme explica o autor, nosso conhecimento da realidade não se restringe à apreensão direta das situações: inclui a capacidade que os humanos têm de avaliar as situações em relação à realidade. Em outras palavras, não é com base na real evolução do mundo que uma dada situação é tida como pertencente ou não à realidade. Cabe ao conceptualizador conhecer, ou não, aceitar, ou não, tal situação como parte da sequência evolutiva, o que se dá a partir de uma avaliação epistêmica que se fundamenta no reconhecimento que os humanos têm da natureza dinâmica da realidade. Sob esse viés, o autor postula uma concepção mais abstrata e inclusiva da realidade, dado que ao processo de conceptualização são acrescentados aspectos relacionados ao conhecimento daquilo que não ocorreu, daquilo que poderá ocorrer e daquilo que poderia ter ou não ocorrido.

Para Langacker (1991), há então, pelo menos, dois níveis e duas noções de realidade a serem considerados: o nível em que as situações são diretamente apreendidas e o nível das proposições que correspondem, respectivamente, às noções de realidade básica e de realidade elaborada. Para ilustrar esses níveis e noções, tomemos como exemplos manchetes de duas notícias que tratam de uma mesma situação:

(1)

Correio Braziliense

Covid-19: 'Já temos imunidade de rebanho', diz Ibaneis

Segundo Secretaria de Saúde, taxa de ocupação dos 643 leitos destinados a pacientes com a doença é de $58,26 \%$

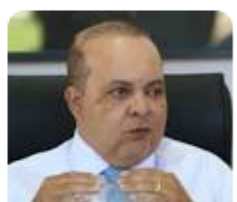

Disponível em: https://www.correiobraziliense.com.br/cidades-df/2020/09/4877870-covid-19-ja-temos-imunidadede-rebanho-diz-ibaneis.html (Acesso em 26/09/2020).

(2)

dP Jovem Pan

Imunidade de rebanho contra Covid-19 só deve chegar com vacina, diz infectologista

Após análises, cientistas acreditam que até $66 \%$ da população de Manaus já teriam anticorpos contra o coronavírus.

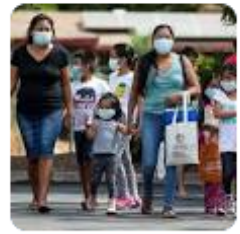

Disponível em: https://jovempan.com.br/programas/jornal-da-manha/imunidade-rebanho-covid-19-chegarvacina.html (Acesso em 26/09/2020). 
Em (1) e (2) vemos que, diante de uma mesma situação, a pandemia provocada pela Covid-19, autoridades de saúde se posicionam diferentemente em relação à 'imunidade de rebanho', que, segundo especialistas, arrefeceria o contágio pelo referido vírus. Dito de outra forma, temos uma realidade básica, que diz respeito à situação apreendida, e a realidade elaborada, que se evidencia nas proposições, ou seja, nas manchetes dos informativos on-line, que incorporam, conforme destacamos, o conhecimento de mundo e a capacidade que os humanos possuem de avaliar as situações em relação à realidade. Em (1), o uso do presente do indicativo precedido de um advérbio de tempo ('já temos') situa a imunidade de rebanho no plano da realidade factual; em (2), por outro lado, o emprego do modal 'dever' ('deve chegar') sinaliza que a imunidade de rebanho ainda não foi atingida, isto é, não pertence à realidade factual, estando, portanto, no plano da irrealidade. Como podemos perceber, a concepção de realidade é relativa. Conceptualizadores diferentes podem ter concepções diferentes de uma situação, conforme ilustram (1) e (2). Assim sendo, no âmbito da Gramática Cognitiva, entende-se que um dado enunciado corresponde à instanciação de uma perspectivação e não, à 'realidade' em si, e é a partir desse entendimento que o enunciado em questão é analisado.

Para abordar as relações entre tempo e concepção de realidade, Langacker (1991) recorre a modelos estruturados do mundo (structured world models), como o que se segue, que ilustra a concepção da realidade em seu nível mais básico.

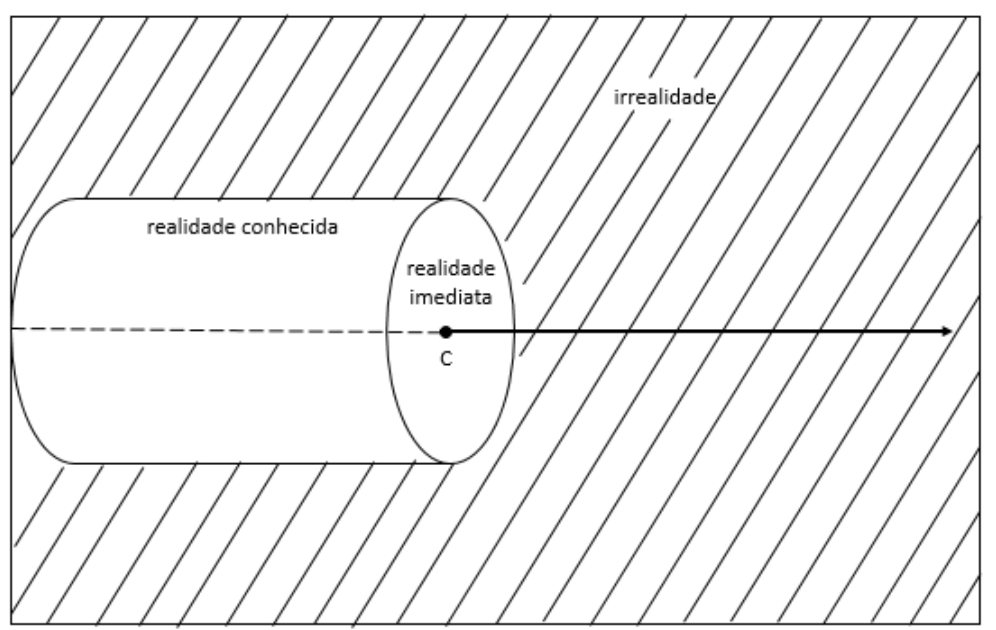

Figura 1. Modelo epistêmico básico. Fonte: LANGACKER (1991).

No modelo epistêmico básico, visualizamos um cilindro que se divide em realidade conhecida, que corresponde ao passado, e em realidade imediata, que diz respeito ao presente e ao ponto onde se encontra o conceptualizador (C). É do ponto de vista da realidade imediata que o conceptualizador (falante ou escrevente) apreende a situação a que se refere. Tudo mais, como podemos constatar, está no plano da irrealidade. Logo, sob 
a ótica do modelo epistêmico básico, em (2), a imunidade de rebanho é situada fora do plano da realidade. Contudo, como podemos perceber, essa bipartição é por demais simplista. Não abarca satisfatoriamente o uso do modal em (2), em que a imunidade de rebanho é referida como uma possibilidade futura, além de outros vieses relacionados a nossa concepção de realidade. Langacker (1991) propõe então outros três modelos que incorporam aspectos não capturados pelo modelo epistêmico básico.

No Modelo epistêmico elaborado, apresentado a seguir, o núcleo da realidade conhecida é envolvido por uma faixa que abarca situações cuja existência o conceptualizador não aceita como tendo sido estabelecida e ainda aquelas situações que, devido ao seu conhecimento limitado e incompleto da realidade, o conceptualizador desconhece.

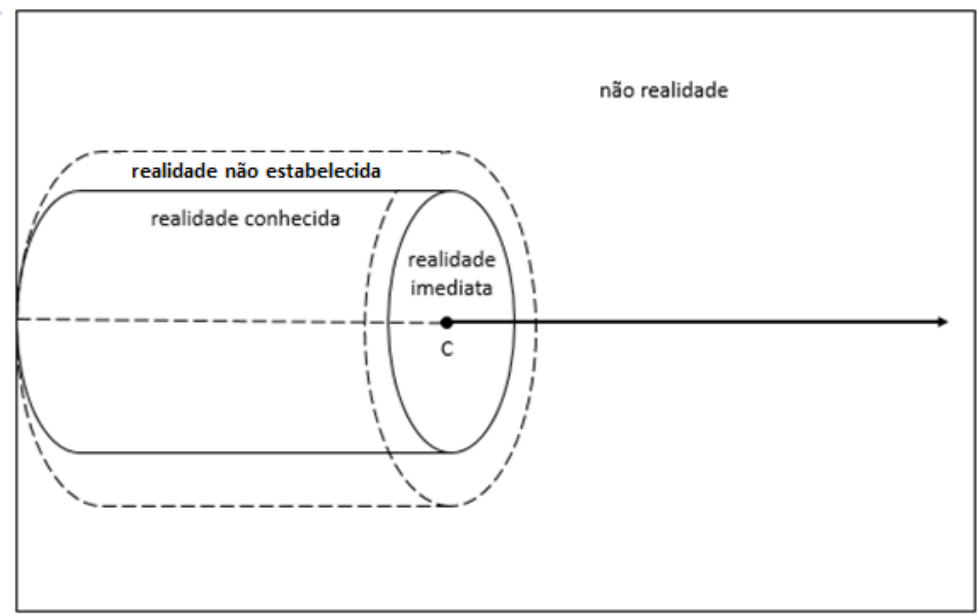

Figura 2. Modelo epistêmico elaborado adaptado. Adaptação de LANGACKER (1991).

A faixa, que apresentamos aqui com o rótulo 'realidade não estabelecida', é denominada 'realidade desconhecida' por Langacker (1991). No entanto, em sua explicação sobre o modelo em questão, o autor alega que, em relação ao modelo anterior, o modelo epistêmico elaborado acrescenta:

\begin{abstract}
a percepção do conceptualizador de que a realidade como ele a conhece não é exaustiva do mundo e de sua história evolutiva. O núcleo da realidade conhecida é, portanto, rodeado por uma região muito maior de realidade desconhecida. Incluídas nesta região estão situações de pelo menos dois tipos: aquelas cuja realidade $\mathrm{C}$ suspeita ou contempla, mas não aceita como tendo sido estabelecida; e aquelas das quais ele é totalmente ignorante. Observe que a realidade desconhecida é parte da irrealidade (...) (Langacker, 1991, p. 243.)
\end{abstract}

2 the conceptualizer's realization that reality as he knows it is not exhaustive of the world and its evolutionary history. The core of known reality is thus surrounded by a much larger region of unknown reality Included in this region are situations of at least two sorts: those whose reality $C$ suspects or contemplates but does not accept as having been established; and those of which he is entirely ignorant. Observe that unknown reality is part of irreality (...). 
Com base em tal explicação, concluímos que, também no caso das situações que o conceptualizador desconhece, verifica-se a não aceitação da existência dessas situações como estabelecida, ou seja, nossa ignorância acerca de situações que possam existir implica não aceitarmos como estabelecida a existência de tais situações. Daí optarmos pelo rótulo 'realidade não estabelecida', que entendemos capturar melhor os dois tipos de realidade mencionados por Langacker (1991), em detrimento do rótulo 'realidade desconhecida' empregado por ele.

No terceiro modelo, o modelo da linha do tempo, o autor incorpora duas noções adicionais: a de tempo (t), ou seja, o eixo ao longo do qual a realidade evolui, e a de ground $(G)$, que se refere ao ato de fala e suas circunstâncias.

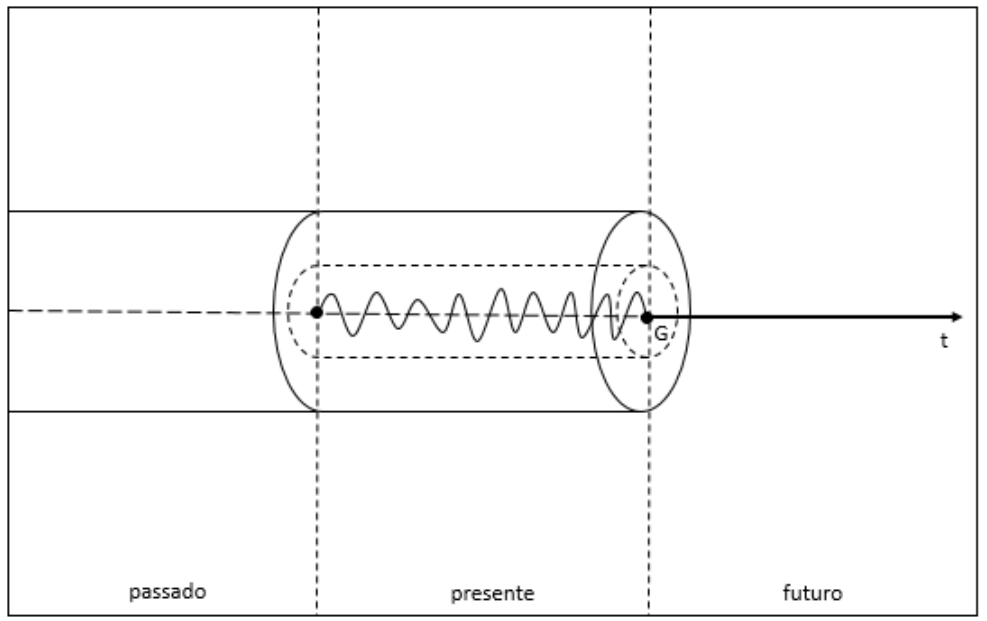

Figura 6. Modelo da linha do tempo. Fonte: LANGACKER (1991, p. 244).

No modelo da linha do tempo, evidencia-se que o locus de um evento de fala instaurase na realidade imediata, onde se encontram falante e ouvinte(s). Ademais, conforme ilustrado neste modelo,

\footnotetext{
Um ato de fala não é pontual. Tem uma duração temporal breve, como indica a linha sinuosa. $O$ tempo é segmentável em passado, presente e futuro e, uma vez que a realidade compreende o passado e o presente, e a realidade imediata constitui o presente, a realidade não imediata corresponde ao passado. (SOUZA; ABRAÇADO; 2020, p. 29)
}

Em seu quarto modelo, denominado modelo evolutivo dinâmico, Langacker (1991) busca dar conta de situações como a exemplificada em (2), com o emprego do modal na manchete 'Imunidade de rebanho contra Covid-19 só deve chegar com a vacina'. Tais situações cuja ocorrência consideramos possível, somadas àquelas situações que podemos prever, são capturadas pelo modelo em questão. De acordo com Langacker, há situações predispostas a ocorrerem sempre que surgirem condições apropriadas para tal e, a menos que uma 
certa quantidade de energia seja gasta para se opor à tendência para que ocorram, essas situações de fato ocorrerão.

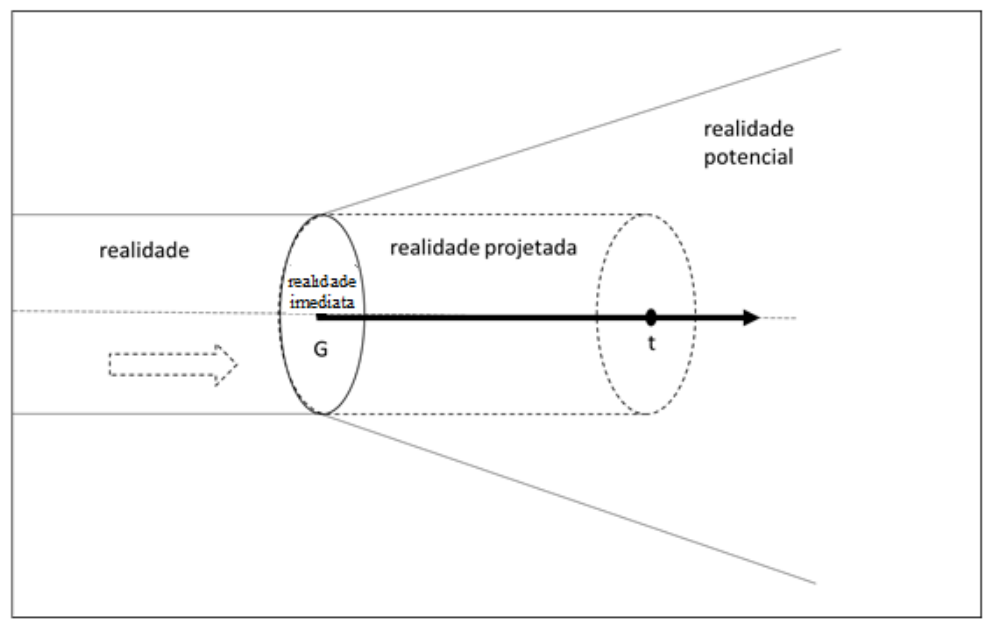

Figura 4. Modelo evolutivo dinâmico. Fonte: LANGACKER (1991, p. 277)

O modelo evolutivo dinâmico, por conseguinte, refere-se a características da realidade que tendem a impulsioná-la para certos caminhos no futuro em detrimento de outros. $\mathrm{O}$ impulso evolutivo da realidade é representado no modelo pela seta tracejada. Sob essa ótica, as situações cuja realização consideramos apenas possível pertencem à realidade potencial. As situações que, com maior ou menor grau de segurança, podemos prever com base em nosso conhecimento do mundo e em experiências passadas e presentes pertencem à realidade projetada (SOARES DA SILVA, inédito).

Vejamos, no exemplo a seguir, notícia publicada meses antes da Copa do Mundo de Futebol de 2018, em que a seleção brasileira é referida como uma das favoritas ao título por comentaristas esportivos e divide com a seleção alemã a liderança nas casas de apostas.

(3)

\section{ODDS COPA DO MUNDO}

\section{Favoritos na Copa: Brasil ainda mais cotado nas casas de apostas}

Vitória sobre a Alemanha deixa o Brasil "um pouco mais" favorito ao título mundial

Os últimos amistosos entre as seleções mexeram com as cotações dos apostadores para a Copa do Mundo da Rússia.

E a bo a notícia é que o Brasil agora divide o favoritismo com a Alemanha. Isso ocorreu justamente depois da vitória da Seleção comandada por Tite sobre os atuais campeões do mundo em Berlim.

Disponível em: https://www.lance.com.br/odds-copa-do-mundo/saiba-quem-sao-favoritos-nas-casas-apostaspara-vencer-copa.html (Acesso em 27/09/2020). 
Em (3), vemos que o favoritismo da seleção brasileira - que não se confirma, uma vez que é a seleção francesa que se consagra campeã em final disputada com a seleção da Croácia - tem como respaldo seu desempenho em amistosos com outras seleções, com destaque para sua vitória no jogo contra a seleção alemã, campeã da copa anterior. Entretanto, como não poderia deixar de ser, como pano de fundo de tal favoritismo também está a tradição de vitórias e de bom futebol da seleção do Brasil.

Semelhantemente, em nossa referência a um evento futuro, com o respaldo do nosso conhecimento de mundo e de acontecimentos passados e/ou recentes - que correspondem ao impulso evolutivo da realidade, representado pela seta tracejada no modelo evolutivo dinâmico -, atribuímos um estatuto epistêmico ao evento em questão, situando-o na realidade projetada, se podemos prever sua realização, ou na realidade potencial, se julgamos sua realização apenas possível, como ilustram, respectivamente, (4) com 'vai abrigar' e (5) com 'podem estar':

(4) Realidade projetada

(2) GAZ

Restaurada, Casa de Cultura de Vera Cruz vai abrigar museu

Restaurada, Casa de Cultura de Vera Cruz vai abrigar museu. Após término da obra de restauro, local receberá acervo

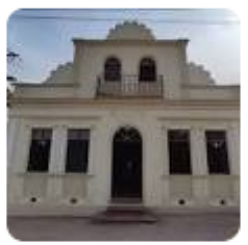

Disponível em: http://www.gaz.com.br/conteudos/regional/2020/09/25/171105-

restaurada_casa_de_cultura_de_vera_cruz_vai_abrigar_museu.html.php (Acesso em 27/09/2020).

(5) Realidade potencial

Ạ̛: Educação Estadão

Clima e crise de saúde podem estar na Redação do Enem

"Nas redações do Enem, o tema sempre vem com uma proposta de intervenção social da atualidade, por isso é importante estar por dentro do

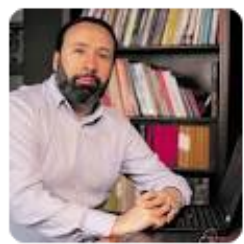

Disponível em: https://educacao.estadao.com.br/noticias/geral,clima-e-crise-de-saude-podem-estar-naredacao,70003516479 (Acesso em 06/12/2020).

Vemos, portanto, que exprimimos nossa avaliação em relação ao estatuto de realidade de uma situação servindo-nos de expressões adverbiais, de expressões modais e, é claro, do modo e do tempo gramaticalizados nas formas verbais, alvos de nosso interesse. Vejamos, então, as relações que se estabelecem em português entre tempo verbal, modo verbal e concepção de realidade. 


\section{TEMPO VERBAL, MODO VERBAL E CONCEPÇÃO DE REALIDADE EM PORTUGUÊS}

Considerando os modelos cognitivos postulados por Langacker, quando pensamos ou falamos sobre uma dada situação, atribuímos-Ihe um estatuto epistêmico, caracterizandoa como factual, previsível, possível ou não. Dessa caracterização resulta a localização da situação em um dos planos ilustrados no Quadro 1:

\begin{tabular}{|c|c|c|}
\hline PASSADO & PRESENTE & FUTURO \\
\hline \multicolumn{2}{|c|}{ REALIDADE NÃO ESTABELECIDA } & REALIDADE POTENCIAL \\
\hline \multirow{2}{*}{\multicolumn{2}{|c|}{ Modo subjuntivo }} & Modo subjuntivo \\
\hline & & Verbos modais \\
\hline \multicolumn{2}{|c|}{ REALIDADE FACTUAL } & REALIDADE PROJETADA \\
\hline \multicolumn{2}{|c|}{ Modo indicativo } & Modo indicativo \\
\hline
\end{tabular}

Quadro 1. Relação entre tempo, modo e concepção de realidade em português.

De acordo com o Quadro 1, se a situação é situada no plano da realidade passada ou da realidade imediata e caracterizada como factual, em sua referência empregamos o modo indicativo e as formas verbais, simples ou compostas, referentes ao passado (pretérito perfeito, pretérito imperfeito e pretérito mais que perfeito) e ao presente (presente simples e presente progressivo). Cumpre ressaltar que o presente do indicativo também é utilizado para referência a eventos passados e futuros. No primeiro caso, os eventos referidos são situados na realidade passada e factual e, em geral, excetuando-se os casos abarcados pelo presente histórico, pertencem ao passado recente, como ilustrado em (9); no segundo caso (que ilustraremos mais adiante), os eventos, que tendem a ocorrer num futuro próximo e a carrear um grau de certeza epistêmica mais elevado do que as demais formas de referência ao futuro ${ }^{3}$, situam-se na realidade projetada.

(6) Realidade passada (pretérito perfeito): 'Chegou a hora...'

Portal Veneza

Chegou a hora de tirar a ideia de startup do papel

Dar o primeiro passo pode ser o mais difícil na hora de começar o próprio negócio.

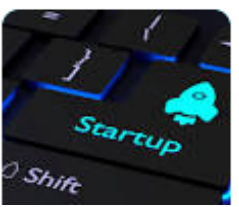

Disponível em: https://www.portalveneza.com.br/chegou-a-hora-de-tirar-a-ideia-de-startup-do-papel/ (Acesso em: 04/10/2020).

3 Ver em Langacker (2002), Brisard (2002), Abraçado (2020) discussão sobre os usos do tempo presente sob a perspectiva da Gramática Cognitiva. 
(7) Realidade passada (pretérito imperfeito): '... quando fazia live...' Capital News

\section{Candidato é roubado quando fazia live na fronteira de MS} $\cdots$

Veja abaixo o vídeo dela e a live do marido, que termina quando um rapaz passa correndo atrás dele e leva o celular que fazia a transmissão.

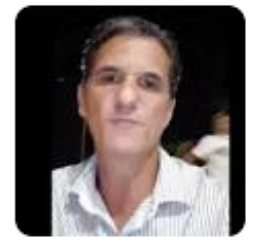

Disponível em: https://capitalnews.com.br/colunistas/marco-eusebio/candidato-e-roubado-quando-fazia-live-nafronteira-de-ms-com-o-paraguai-video/348231 (Acesso em: 19/10/2020).

(8) Realidade passada (pretérito mais que perfeito): ' ... fizera o mesmo percurso...'

Jornal O Globo

$\mathrm{XP}$ já investiu R\$ 1 bilhão com para reter agentes autônomos

Dois meses atrás, a EQI, um dos maiores agentes autônomos da XP fizera o mesmo percurso. Mas mudanças assim tendem a ser mais raras.

Disponível em: https://blogs.oglobo.globo.com/lauro-jardim/post/xp-ja-investiu-r-1-bilhao-com-para-reter-agentesautonomos.html (Acesso em: 04/10/2020).

(9) Realidade passada (presente simples): 'Justiça inaugura...'

\section{G1 $\mathrm{G} 1$}

Justiça inaugura uso de plataforma para otimizar serviços em comarcas da Zona da Mata e Vertentes

O Tribunal de Justiça de Minas Gerais (TJMG) inaugurou nesta quinta-feira (15) o uso da plataforma do Processo Judicial eletrônico (PJe) no ...

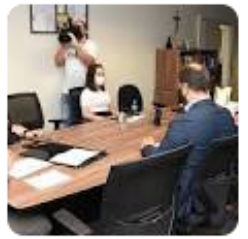

Disponível em: https://g1.globo.com/mg/zona-da-mata/noticia/2020/10/16/justica-inaugura-uso-de-plataformapara-otimizar-servicos-em-comarcas-da-zona-da-mata-e-vertentes.ghtml (Acesso em: 16/10/2020).

(10) Realidade imediata (presente simples): 'Google quer...'

(a) Canaltech

Google quer "busca perfeita" e refina seus mecanismos $\cdots$

Google quer "busca perfeita" e refina seus mecanismos de pesquisa com (muita) IA. Por Rui Maciel| 15 de Outubro de 2020 às 19h50. Matheus

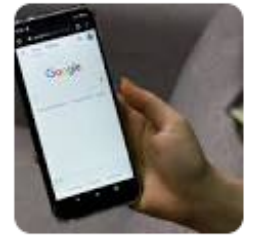
Argentoni/ .

Disponível em: https://canaltech.com.br/internet/em-busca-da-busca-perfeita-google-refina-mecanismo-depesquisa-com-muita-ia-173120/ (Acesso em: 19/10/2020). 
(11) Realidade imediata (presente progressivo): 'A confiança está voltando...'

Opinião Estadão

\section{A confiança está voltando ao comércio paulista}

A confiança está voltando ao comércio paulista. Políticas de transferência

de renda, como o auxílio emergencial, tiveram papel decisivo no ...

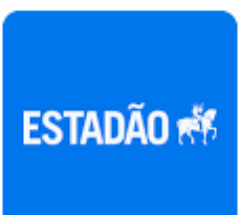

Disponível em: https://opiniao.estadao.com.br/noticias/editorial-economico,a-confianca-esta-voltando-aocomercio-paulista,70003467629 (Acesso em: 19/10/2020).

No caso de situações passadas ou presentes que não são conceptualizadas como factuais, as seguintes combinações entre tempo e modo sinalizam que tal situação pertence ao plano da realidade não estabelecida: (i) futuro do pretérito, no modo indicativo; (ii) pretérito imperfeito, pretérito perfeito e pretérito mais que perfeito, no modo subjuntivo; e (iii) presente, no modo subjuntivo.

(12) Realidade não estabelecida (futuro do pretérito do indicativo): '...cocaína que seguiria...'

MS Enfoque MS

PMR apreende quase $100 \mathrm{~kg}$ de cocaína que seguiria para São Paulo

Durante a Operação Hórus, desencadeada pela SEJUSP/MS e pela

Secretaria Nacional de Operações Integradas (SEOPI) do Ministério de ..

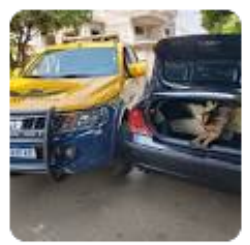

Disponível em: https://www.enfoquems.com.br/pmr-apreende-quase-100-kg-de-cocaina-que-seguiria-para-sp/ (Acesso em: 19/10/2020).

(13) Realidade não estabelecida (pretérito imperfeito do subjuntivo): '...que o cliente tivesse um plano...'

G1 $\mathrm{G} 1$

Advogado de André do Rap nega que cliente tinha plano de fuga: 'Essa história é um folclore'

... o André do Rap, de 43 anos, que está foragido desde sábado (10), nega que o cliente tivesse um plano de fuga para escapar do Brasil.

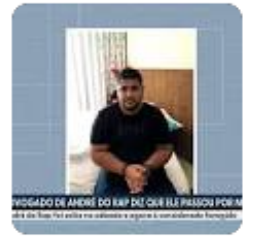

Disponível em: https://g1.globo.com/pr/norte-noroeste/noticia/2020/10/15/advogado-de-andre-do-rap-nega-quecliente-tinha-plano-de-fuga-essa-historia-e-um-folclore.ghtml (Acesso em: 19/10/2020). 
(14) Realidade não estabelecida (pretérito perfeito do subjuntivo): ' ...que essa conversa tenha acontecido'
Af: Política Estadão
Postagem inventa diálogo entre Papa Francisco e Bolsonaro sobre a Amazônia
Não há nenhum registro, na imprensa ou nas redes sociais, de que essa conversa tenha acontecido.

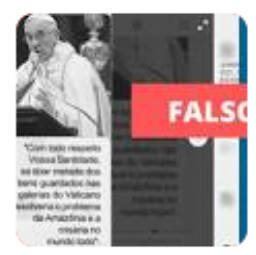

Disponível em: https://politica.estadao.com.br/blogs/estadao-verifica/postagem-inventa-dialogo-entre-papafrancisco-e-bolsonaro-sobre-a-amazonia/_(Acesso em: 19/10/2020).

(15) Realidade não estabelecida (pretérito mais que perfeito do subjuntivo): 'Se tivesse visto...'

\section{Se tivesse visto o empurrão, o arbitro apitaria e não teria gol 23 de set. de 2014 - O atacante Fred, do Fluminense, foi um dos protagonistas das sempre constantes polêmicas de arbitragem nas rodadas do Campeonato ... colunadofla.com > 2014/09 > se-tivesse-visto-o-empurr...}

Disponível em: https://colunadofla.com/2014/09/se-tivesse-visto-o-empurrao-o-arbitro-apitaria-e-nao-teriagol/(Acesso em: 22/10/2020).

(15) Realidade não estabelecida (presente do subjuntivo): 'Sandra Annenberg nega que esteja...'

J⿳一巛工 Jornal da Manhã - Uberaba

\section{Sandra Annenberg nega que esteja de saída da Globo}

Negou. Sandra Annenberg nega que esteja de saída da Globo. Atualmente ela comanda o Globo Repórter às sextas-feiras.

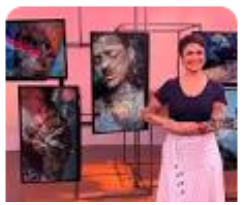

Disponível em: https://imonline.com.br/novo/?paginas/colunas,134,201584_(Acesso em: 19/10/2020).

No que diz respeito à referência a situações futuras, o quadro é o seguinte: situamos uma dada situação futura na realidade projetada, se podemos prever sua realização, ou na realidade potencial, se julgamos sua realização apenas possível; ao situarmos uma situação no plano da realidade projetada, valemo-nos das formas verbais de futuro e, conforme já mencionamos, também do presente, no modo indicativo; quando situamos uma situação futura no plano da realidade potencial, empregamos o futuro do subjuntivo e também os verbos modais. 
(16) Realidade projetada (futuro do presente do indicativo): 'Calor chegará...'

is iBahia

Calor chegará forte em Salvador durante o mês de outubro, dizem especialistas

Calor chegará forte em Salvador durante o mês de outubro, dizem especialistas. Tendência dessa época do ano é o aumento das

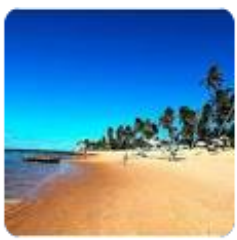

Disponível em: https://www.ibahia.com/salvador/detalhe/noticia/calor-chegara-forte-em-salvador-durante-o-mesde-outubro-dizem-especialistas/ (Acesso em: 19/10/2020).

(17) Realidade projetada (presente do indicativo): '...começa amanhã'.

CP Jornal Correio do Povo

\section{Simpósio Online de Fruticultura começa amanhã}

Simpósio Online de Fruticultura começa amanhã. Evento se estende até 23 de outubro

Disponível em: https://www.correiodopovo.com.br/not\%C3\%ADcias/rural/simp\%C3\%B3sio-online-de-fruticulturacome\%C3\%A7a-amanh\%C3\%A3-1.500961 (Acesso em: 19/10/2020).

(18) Realidade potencial (futuro do subjuntivo): 'Quando tudo der...'

\section{8 coisas para se lembrar quando tudo der errado}

4 de jun. de 2014 - Hoje, estou sentada na minha cama de hospital à espera de ter meus seios removidos. Mas de uma forma estranha eu me sinto sortuda.

Disponível em: https://jornaldoempreendedor.com.br/destaques/inspiracao/8-coisas-para-se-lembrar-quandotudo-der-errado/ (Acesso em: 19/10/2020).

Com base no exposto até então, podemos concluir que a localização temporal de uma dada situação está diretamente relacionada ao estatuto epistêmico que lhe é atribuído, o que envolve não somente a ocorrência da situação em si, mas também o conhecimento de mundo dos conceptualizadores, locutor e interlocutor(es), envolvidos no ato comunicativo. Por conseguinte, quando falamos de predicações temporalmente marcadas, estamos na verdade falando de predicações epistêmicas, dado o estatuto epistêmico da situação que carreiam.

Faz-se também necessário ressaltar que, além dos tempos verbais que apontam para intervalos de tempo anteriores, simultâneos ou posteriores ao tempo do ato de fala e, por isso, caracterizados como dêiticos, há os tempos verbais anafóricos que se referem a localizações temporais construídas a partir de pontos de referência discursivamente instituídos, mas que, no entanto, preservam as mesmas relações de anterioridade, simultaneidade e posteridade dos tempos dêiticos (SOARES DA SILVA, inédito,).

Em (19), a seguir, há dois pontos de referência discursivamente instituídos (1981 e 2019) e a forma verbal 'contava' refere-se anaforicamente ao time do Flamengo do ano de 1981. 
(19)

O Terra

A diferença do Flamengo de 1981 para o vice de 2019:

Zico

No título mundial do Flamengo de 1981, o time contava com aquele que

talvez fosse, à época, o principal jogador de futebol do planeta: Zico.

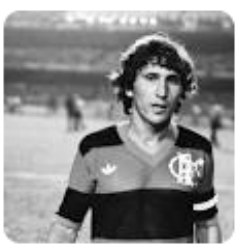

Disponível em: https://www.terra.com.br/esportes/flamengo/a-diferenca-do-flamengo-de-1981-para-o-vice-de2019-zico,769a68ebe9cd63dc2a36752ca8e427a4dlpiqmgk.html

Há ainda em (19) um outro aspecto a ser destacado. Enquanto a forma verbal 'contava', no pretérito imperfeito do indicativo, indica que o conceptualizador situa o time do Flamengo de 1981 no âmbito de uma realidade factual, a forma verbal 'fosse', no pretérito imperfeito do modo subjuntivo, alinhada com o advérbio de dúvida 'talvez', sinaliza que a condição de Zico ser o principal jogador do planeta, na ocasião referida, não é concebida pelo conceptualizador como uma situação estabelecida. Vemos, portanto, que também nas localizações temporais discursivamente construídas, a relação entre tempo, modo e concepção de realidade se mantém.

Por fim, chamamos a atenção para usos bastante corriqueiros dos tempos e modos verbais, em que a localização temporal e os diferentes níveis de realidade são indicados por recursos outros que não os próprios tempos e modos gramaticalizados nas formas verbais. Além de corriqueiros, são diversos os usos em que isso pode ocorrer. A título de ilustração, primeiramente em relação à localização temporal, consideremos o emprego do pretérito perfeito em referência a um tempo passado precedente a outro tempo passado, conforme ocorre no exemplo a seguir abordado em trabalho anterior (ABRAÇADO 2020, p. 94):

(20)

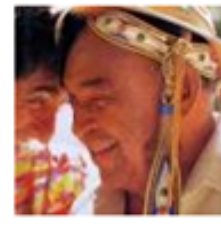

Em entrevista, Fagner resgata amizade e parceria musical com Luiz ...

Diário do Nordeste - 2 de ago de 2019

Nós nos conhecemos antes, mas eu fiquei bem interessado em fazer algo com ele, com aquela formação toda. A principio ele não entendeu, mas quando ele resolveu fazer um disco dele com a nova ger ação que estava surgindo na época, dai ele me convidou. Ele tava a fim de fazer um projeto.

Disponível em: https://diariodonordeste.verdesmares.com.br/editorias/verso/online/em-entrevista-fagner-resgataamizade-e-parceria-musical-com-luiz-gonzaga-1.2130584_(Acesso em: 02/08/2019).

Em (20), a sinalização de anterioridade e posterioridade temporal é feita pelos circunstanciais "antes", "a princípio", "quando" e "na época".

Situação semelhante se dá concernentemente aos diferentes níveis de realidade. Quando o futuro do subjuntivo, por exemplo, ocorre associado a um circunstancial de tempo, a um evento programado ou previsível, as situações então referidas são remetidas 
à realidade projetada (e não, à realidade potencial), como se verifica em (21) com 'quando acabar o campeonato':

(21)

maisfutebol.iol.pt , Últimas , Maisfutebol

Ranieri: «O meu trabalho termina assim que acabar o ...

10 de mai. de 2019 - O meu trabalho termina quando acabar o campeonato. Sinto que estou

a promover a Roma, um bem inestimável», afirmou o treinador

Disponível em: https://maisfutebol.iol.pt/internacional/italia/ranieri-o-meu-trabalho-termina-assim-que-acabar-ocampeonato (Acesso em: 19/11/2020).

\section{SUMARIANDO}

Sempre que pensamos ou nos referirmos a uma situação, atribuímos-lhe um estatuto de realidade e estabelecemos sua localização temporal (relativa ao ato de fala ou a algum ponto de referência discursivamente instituído). Exprimimos nossa avaliação, no que se refere ao estatuto de realidade de uma situação, servindo-nos de expressões adverbiais, de expressões modais, do modo e do tempo gramaticalizados nas formas verbais. Priorizando o modo e o tempo gramaticalizados nas formas do verbo, vimos que, em português, a relação tempo, modo e concepção de realidade se estabelece de tal forma que:

(i) Se a situação é conceptualizada no plano da realidade passada ou da realidade imediata, em sua referência empregamos o modo indicativo e as formas verbais, simples ou compostas, referentes ao passado (pretérito perfeito, pretérito imperfeito e pretérito mais que perfeito) e ao presente (presente simples e presente progressivo).

(ii) No caso de situações passadas ou presentes que não são conceptualizadas como factuais, nos valemos das seguintes combinações entre tempo e modo para sinalizar que tal situação pertence ao plano da realidade não estabelecida: (a) futuro do pretérito, no modo indicativo; (b) pretérito imperfeito, pretérito perfeito e pretérito mais que perfeito, no modo subjuntivo; e (c) presente, no modo subjuntivo.

(iii) Quando em referência a uma situação conceptualizada como futura, se pudermos prever sua ocorrência, utilizamos as formas verbais de futuro e do presente simples, no modo indicativo, para situá-la no plano da realidade projetada; se julgamos sua ocorrência apenas possível, empregamos o futuro do subjuntivo e os verbos modais para situarmos tal situação no plano da realidade potencial. 
Obviamente, o processo de conceptualização, ou seja, a apreensão, em termos cognitivos, de uma dada entidade ou situação por um conceptualizador, envolve muitos outros aspectos que, justamente por serem muitos, não foram capturados neste texto. Cumpre, contudo, destacar que todo e qualquer processo de conceptualização envolve modos alternativos de se conceptualizar determinada situação (construals, para Langacker 1991, 1999 e 2002), que subjazem, portanto, a relação entre tempo, modo e concepção de realidade aqui focalizada.

\section{AGRADECIMENTOS}

Agradeço à CAPES, pela bolsa de Pós-Doutoramento, e ao CNPq, pela bolsa de Produtividade em Pesquisa, que me foram concedidas e que propiciaram o desenvolvimento de estudos dos quais se originou este texto.

\section{REFERÊNCIAS}

ABRAÇADO, Jussara. O tempo, o tempo linguístico e o tempo verbal: propriedades e relações. São Paulo: Contexto, 2020.

BRISARD, Frank. The English present. BRISARD, Frank (ed.) Grounding: the epistemic footing of deixis and reference. Berlin/New York: Mouton de Gruyter, 2002, p. 251-297.

FONSECA, Fernanda I. Dêixis e Pragmática Linguística. FARIA, Isabel Hub; PEDRO, Emília Ribeiro; DUARTE, Inês, Gouveia; Carlos A.M. (Orgs.). Introdução à Linguística Geral e Portuguesa. Lisboa: Caminhos, 1996, p. 437-445.

LANGACKER, Ronald W. Foundation of cognitive grammar. Volume II: Descriptive Aplication. California: Stanford University Press, 1991.

Losing control: grammaticization, subjectification, and transparency. BLANK, Andreas; KOCH, Peter (Eds.). Historical Semantics and Cognition. Berlin: Mouton de Gruyter, 1999, p.147-175.

. The English present tense. English Language and Linguistics 5: 251-272. 2002.

Extreme subjectification: English tense and modals. CUYCKENS Hubert; BERG, Thomas; DIRVEN, René; PANTHER, Klaus-Uwe (Eds.). Motivation in Language: Studies in honor of Günter Radden. Amsterdam: John Benjamins, 2003, p. 3-26.

SOARES DA SILVA, Augusto. O Significado na Linguagem e na Mente. Uma Introdução à Semântica. Braga: Universidade Católica Portuguesa, 320 páginas (inédito).

SOUZA; Melina; ABRAÇADO, Jussara. A projeção do tempo futuro em frames de finalidade. DIAS, Nilza; ABRAÇADO, Jussara (orgs.). Estudos sobre o português em uso. Uberlândia: Pangeia, 2020, p.43-77. Disponível em: https://www.academia.edu/43968444/A_PROJE\%C3\%87\%C3\%830_DO_TEMPO_FUTURO_EM_FRAMES_DE_FINALI DADE. Acesso em 20/10/2020. 